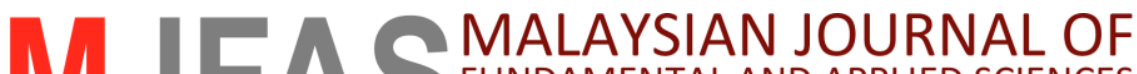 FUNDAMENTAL AND APPLIED SCIENCES \\ PRINT ISSN: 2289-5981 | ONLINE ISSN: 2289-599X
}

\section{Controlled physical and optical traits of magnesium-zinc sulphophosphate glass: Role of europium ions}

\author{
Ibrahim Mohammed Danmallam a, b, Sib Krishna Ghoshal a ${ }^{*}$, Ramli Ariffin a, Siti Aisha Jupri a, \\ Sunita Sharma ${ }^{\mathrm{c}}$
}

a Advance Optical Materials Research Group, Faculty of Science, Department of Physics, Universiti Teknologi Malaysia, 81310 UTM Johor Bahru, Johor, Malaysia

b Sokoto Energy Research Center, Usmanu Danfodiyo University Sokoto, Sokoto, Nigeria

Department of Applied Sciences, The North Cap University, Gurgaon, Haryana, India

* Corresponding author: sibkrishna@utm.my

\section{Article history}

Received 3 May 2018

Revised 25 August 2018

Accepted 11 September 2018

Published Online 25 October 2018

\section{Graphical abstract}

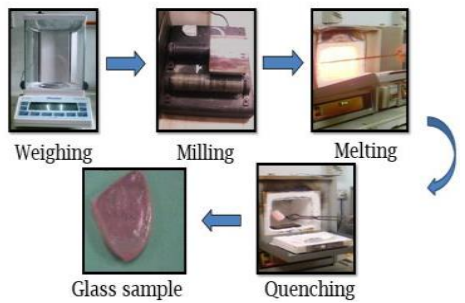

\begin{abstract}
Trivalent rare earth ions doped sulfophosphate glasses became demanding owing to their several notable attributes that are advantageous for diverse photonic devices. To fulfil such goal, preparation of sulfophosphate glasses with optimized composition by selecting appropriate modifier and subsequent characterizations are essential. Driven by this idea, we synthesized a new series of europium $\left(\mathrm{Eu}^{3+}\right)$ ions doped magnesium-zinc-sulfophosphate glasses of composition $(65-x) \mathrm{P}_{2} \mathrm{O}_{5}-20 \mathrm{MgO}-15 \mathrm{ZnSO} \mathrm{O}_{4}-x \mathrm{Eu}_{2} \mathrm{O}_{3}(x$ $=0.0,0.5,1.0,1.5$ and $2.0 \mathrm{~mol} \%)$ using simple melt-quenching method. As-prepared glasses were characterized thoroughly at room temperature via various analytical techniques to determine the $\mathrm{Eu}_{2} \mathrm{O}_{3}$ concentration-dependent physical and optical properties. Transparent (pinkish) and thermally stable glasses were achieved. XRD pattern confirmed the amorphous nature of the studied glasses. Glass density was increased from 2.603 to $2.789 \mathrm{~g} / \mathrm{cm}^{-3}$ with the increase of $\mathrm{Eu}_{2} \mathrm{O}_{3}$ contents from 0 to $2.0 \mathrm{~mol} \%$. FTIR spectra revealed the characteristics bonding vibrations (symmetric and asymmetric stretching and bending of $v_{S}(\mathrm{P}-\mathrm{O}), v_{\mathrm{aS}}(\mathrm{P}-\mathrm{O}-\mathrm{P}), v_{\mathrm{S}}(\mathrm{P}-\mathrm{O}-\mathrm{P}), v_{\mathrm{S}} \mathrm{P}_{3} \mathrm{O}, v_{\mathrm{S}}(\mathrm{P}-\mathrm{O}-\mathrm{P})$ of phosphate networks linkages. The UV-Vis-NIR spectra of the glasses disclosed six significant absorption peaks centred at $360,380,394,414,465$, and $531 \mathrm{~nm}$ accompanied by two NIR peaks around 2091 and $2205 \mathrm{~nm}$ allocated to various transitions from the ground state to the excited states of $\mathrm{Eu}^{3+}$ ion. Furthermore, the optical absorption data were further used to calculate the energies of direct $(2.0$ to $3.85 \mathrm{eV})$ and indirect $(3.74$ to $5.0 \mathrm{eV})$ band gap as well as Urbach energies $(0.1909$ to $0.2440 \mathrm{eV})$. The photoluminescence $(\mathrm{PL})$ emission spectra of glasses displayed four peaks entered at $593,613,654$ and $701 \mathrm{~nm}$ assigned to the ${ }^{5} \mathrm{D}_{0 \rightarrow}{ }^{7} \mathrm{~F}_{0}{ }^{5} \mathrm{D}_{0 \rightarrow}{ }^{7} \mathrm{~F}_{2}{ }^{5} \mathrm{D}_{0 \rightarrow}{ }^{7} \mathrm{~F}_{3}$ and ${ }^{5} \mathrm{D}_{\mathrm{o} \rightarrow}{ }^{7} \mathrm{~F}_{4}$ transitions of Eu ${ }^{3+}$ ion. The PL peak at $613 \mathrm{~nm}$ showed the highest emission intensity. The PL intensity was enhanced with the increase of $\mathrm{Eu}^{3+}$ content up to $1.5 \mathrm{~mol} \%$ and quenched thereafter. It was concluded that controlled physical and optical properties can be obtained by appropriately optimizing the glass composition useful for photonic purposes.
\end{abstract}

Keywords: Europium, bandgap, Urbach energy, absorption, photoluminescence

\section{INTRODUCTION}

Phosphate glasses are superior to silicate and borate glasses are due to higher thermal stability, density, limited melting point, dispersion, high solubility and ultraviolet cut-off (Ahmadi, Hussin and Ghoshal, 2017; Mott and Davis, 1971; Ashur et al., 2013). Phosphate glasses have been widely used in displays, sensors, lasers and amplifiers. Rare earth ions (REIs) doped phosphate glasses have higher refractive index and low phonon energy which make them suitable for optical memory and photonic applications (Reza Dousti et al., 2013). However, the optical, physical and structural properties of these REIs doped glass systems are decided by their chemical compositions that requires optimization. The spectral properties of these glass systems very much depend on the excited states energy level positions and branching ratios of the REIs (Dimitrov et al., 1996). The high luminescence of europium ion $\left(\mathrm{Eu}^{3+}\right)$ is due to its specific energy levels that can be coupled with sensitive structural surrounding provided by the complex amorphous network. Certainly, unique characteristics of $\mathrm{Eu}^{3+}$ are fundamental for the development of laser, displays, up-converters and fibre amplifiers (Snitzer, 1961). Sharp red-light emission and longer lifetime of $\mathrm{Eu}^{3+}$ are distinct from other REIs. Simple and non-degenerate ground state ${ }^{7} \mathrm{~F}_{0}$ and excited state ${ }^{5} \mathrm{D}_{0}$ are involved in the absorption and emission processes (Koester and Snitzer, 1964; Yajima, H., Kawase, S., Sekimoto, 1972; Saruwatari, M., 1974), where rich red colour display in devices is due to ${ }^{5} \mathrm{D}_{0} \rightarrow{ }^{7} \mathrm{~F}_{2}$ transition. Symmetry or homogeneity in various host matrices can easily accommodate such simple energy level structure and induce allowed transitions in $\mathrm{Eu}^{3+}$ (Saruwatari, M., 1974; Stambouli et al., 2013). However, low absorption coefficient of $\mathrm{Eu}^{3+}$ and low emission efficiency in the UV region are being the major limitations need improvement. One strategy is the increase of REIs concentrations, co-doping and/or co-embedment of metal nanoparticles. In both cases, concentration dependent intensity quenching persists, which can be minimized via composition optimization. The improvement in the overall properties of $\mathrm{Eu}^{3+}$ doped phosphate glasses can be attributed to 
energy transfer between dipole or cluster formation (Yajima, H., Kawase, S., Sekimoto, 1972; Saruwatari, M., 1974). Despite many efforts the influence of varying $\mathrm{Eu}^{3+}$ contents on the physical and optical properties of magnesium-zinc-sulfophosphate glasses have not been clearly understood. In this view, a new series of $\mathrm{Eu}^{3+}$ ions doped magnesium-zinc-sulfophosphate glasses of composition $(65-x) \mathrm{P}_{2} \mathrm{O}_{5}$ $20 \mathrm{MgO}-15 \mathrm{ZnSO}_{4}-x \mathrm{Eu}_{2} \mathrm{O}_{3}(x=0.0,0.5,1.0,1.5$ and $2.0 \mathrm{~mol} \%)$ were prepared using simple melt quenching method. Prepared samples were characterized at room temperature via different analytical tools. The effects of changing $\mathrm{Eu}_{2} \mathrm{O}_{3}$ concentration on the physical and optical properties of the glasses were determined.

\section{METHODOLOGY}

The amorphous nature of samples was confirmed using Bruker D8 Advance diffractometer (XRD, $K_{\alpha}=1.54 \dot{A}$ ) at $40 \mathrm{kV}$ and $100 \mathrm{~mA}$. The functional groups of the samples were detected by Fourier Transform Infrared (FTIR) analyses which were performed using Perkin Elmer Paragon 500 FTIR spectrophotometer with a resolution of $\pm 4.0 \mathrm{~cm}^{-1}$ in the wave number range $400-4000 \mathrm{~cm}^{-1}$. For IR measurement, bulk glasses were ground in powder form, where $1 \mathrm{mg}$ of glass powder was mixed with $\mathrm{KBr}$ powders of $100 \mathrm{mg}$ and pressed to $10 \mathrm{tons} / \mathrm{cm}^{2}$ to form thin transparent pellet. The ultraviolet- visible (UV-Vis) absorption spectra of the glasses in the range of 350-2500 $\mathrm{nm}$ were measured using Shimadzu UVPC-3101 spectrophotometer with a resolution of $\pm 1 \mathrm{~nm}$. Dimitrov and Sakka's relation was used to calculate the refractive index from optical band gap values that were evaluated from the UV-Vis absorption edge by Tauc's plot (Dimitrov et al., 1996). The photoluminescence (PL) emission spectra in the wavelength range of $530-750 \mathrm{~nm}$ (at $476 \mathrm{~nm}$ excitation) were recorded by a Jasco spectrofluorometer (FP-8500 PL spectrometer).

\section{RESULTS AND DISCUSSION}

\section{XRD pattern}

Fig. 1 shows the XRD pattern of typical glasses. The absence of any sharp crystalline peaks and the presence of broad hunch verified the amorphous nature of as-quenched sample (Soga, N., Hirao, K., Yoshimoto, M., Yamamoto, 1988). mol\%) were prepared using meltquenching method. Depending on the $\mathrm{Eu}_{2} \mathrm{O}_{3}$ contents the synthesized glasses were coded as MZSPEu0.0, MZSPEu0.5, MZSPEu1.0, MZSPEu1.5 and MZSPEu2.0 which are summarized in Table 1. Homogeneously mixed constituents were placed in an alumina crucible and melted inside an electrical furnace $\left(1100{ }^{\circ} \mathrm{C}\right)$ for 90 minutes. Upon achieving the desired viscosity, the melt was poured on pre-heated stainless-steel mould and annealed at $300{ }^{\circ} \mathrm{C}$ for 180 minutes. Then, the frozen solid was cooled down to room temperature. The frozen samples were polished to achieve desired transparency and uniform thickness needed for optical measurements.

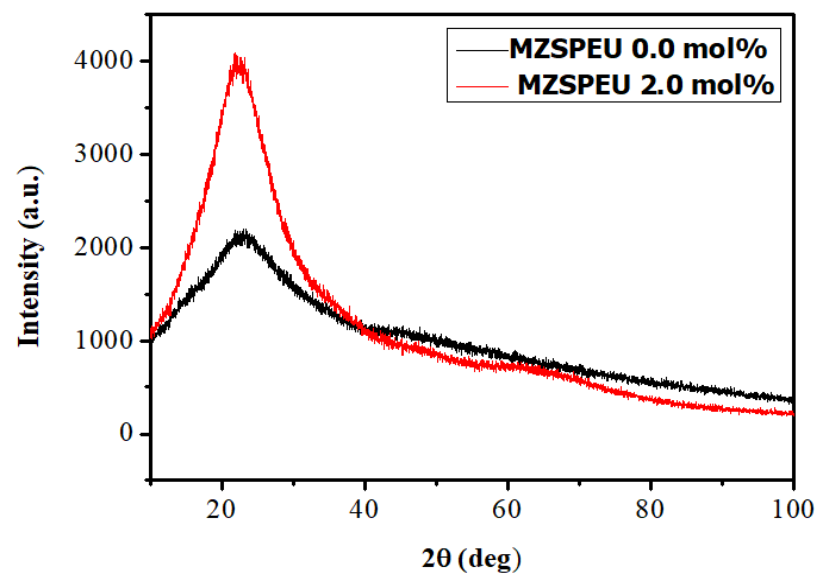

Fig. 1 XRD pattern of MZSPEU0.0 and MZSPEU2.0 glasses.
Table 1: Glass composition and codes.

\begin{tabular}{lllll}
\hline Composition & \multicolumn{3}{c}{ (mol\%) } \\
\hline Glass code & $\mathbf{P}_{\mathbf{2}} \mathbf{O}_{\mathbf{5}}$ & $\mathbf{Z n S O}_{\mathbf{4}}$ & $\mathbf{M g O}$ & $\mathrm{Eu}_{\mathbf{2}} \mathbf{O}_{\mathbf{3}}$ \\
\hline MZSPEu0.0 & 65.0 & 20 & 15 & 0.0 \\
MZSPEu0.5 & 64.5 & 20 & 15 & 0.5 \\
MZSPEu1.0 & 64.0 & 20 & 15 & 1.0 \\
MZSPEu1.5 & 63.5 & 20 & 15 & 1.5 \\
MZSPEu2.0 & 63.0 & 20 & 15 & 2.0 \\
\hline
\end{tabular}

High purity (99.99\% from Sigma Aldrich) reagents all in powder from were used as glass constituents. Glasses of molar composition $(65-\mathrm{x}) \mathrm{P}_{2} \mathrm{O}_{5}-20 \mathrm{MgO}_{2}-15 \mathrm{ZnSO}_{4}-\mathrm{x} \mathrm{Eu}_{2} \mathrm{O}_{3}(\mathrm{x}=0.0,0.5,1.0,1.5$ and 2.0.

\section{Optical properties}

Fig. 2 displays FTIR spectra of the studied glasses, which consisted of several characteristics bands that were assigned to different bonding vibrations summarised as follows: (i) band at $521 \mathrm{~cm}^{-1}$ was allocated to for $\mathrm{P}-\mathrm{O}$ bonds vibration, (ii) band at $755 \mathrm{~cm}^{-1}$ corresponded to the symmetric stretching vibration of P-O-P linkages, (iii) band at $917 \mathrm{~cm}^{-1}$ was due to different groups of metaphosphates, (iv) band at $1109 \mathrm{~cm}^{-1}$ was allotted to the asymmetric stretching vibration of $\mathrm{PO}_{2}$ units, (v) band at $1303 \mathrm{~cm}^{-1}$ was endorsed asymmetric vibration of double oxygen bond in $\mathrm{PO}_{2}$, and (vi) band at $1639 \mathrm{~cm}^{-1}$ were assigned to $\mathrm{H}_{2} \mathrm{O}$ and $\mathrm{OH}$ vibrations in water, respectively. Interestingly, the hygroscopic nature of sulfophosphate glass was reduced with the decrease in $\mathrm{Eu}^{3+}$ contents, responsible for low glass stability due to the generation of more nonbridging oxygen (NBO) bonds.

Table 1: FTIR band assignment of magnesium zinc sulphophosphate glasses.

\begin{tabular}{ccc}
\hline $\begin{array}{c}\text { Bands } \\
\left(\mathrm{cm}^{-1}\right)\end{array}$ & \multicolumn{1}{c}{ Reported } & \multicolumn{1}{c}{ Assignment } \\
\hline 521 & 514 (Reis et al., 2002) & P-O groups \\
755 & 740 (Ahmadi et al., 2017) & $\begin{array}{c}\text { P-O-P asymmetric } \\
\text { linkages }\end{array}$ \\
917 & 980 (Ahmadi et al., 2017) & $\mathrm{P}_{3} \mathrm{O}$ Metaphosphate \\
1109 & 1086 (Rasool et al., 2013) & $\mathrm{PO}_{2}$ asymmetric linkages \\
1303 & 1284 (Ahmadi et al., 2017) & $\mathrm{PO}_{2}$ Double oxygen bond \\
1639 & 1635 (Ahmadi et al., 2017) & $\mathrm{H}_{2} \mathrm{O}$ and OH in water \\
\hline
\end{tabular}

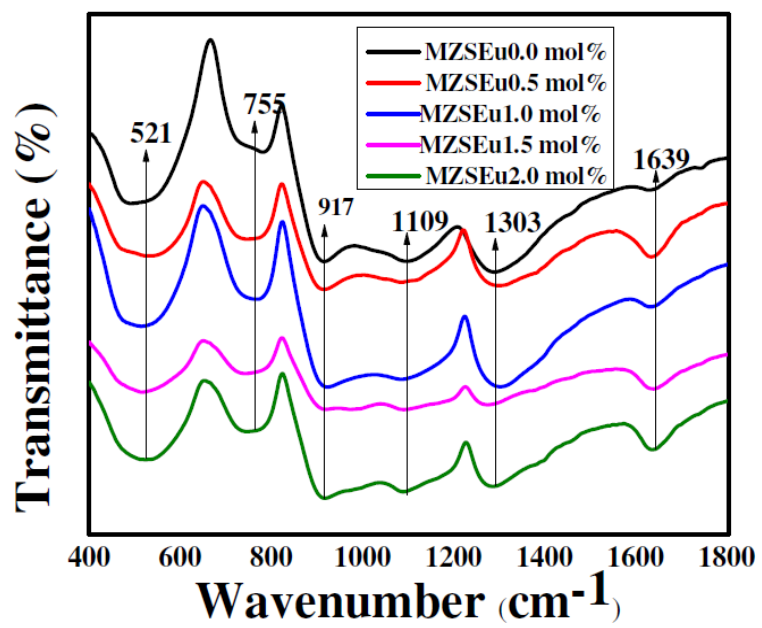

Fig. 2 FTIR spectra of the studied glasses. 
Fig. 3 illustrates the UV-Vis absorption spectra of the studied glasses. It consisted of several peaks originated from the ground state to the excited state transitions of $\mathrm{Eu}^{3+}$ ion. In the visible region all the studied glasses disclosed six significant absorption peaks centred at 360, 380, $394,414,465$, and $531 \mathrm{~nm}$. In the NIR region, two prominent peaks were observed at 2091 and $2205 \mathrm{~nm}$. Irrespective of $\mathrm{Eu}^{3+}$ concentration variation, the spectral transition remained unchanged. This observation was attributed to the weak crystal field interaction in the proposed glass system. The occurrence of inhomogeneous broadening in the absorption peak affirmed the disorder nature of the glass network (Y. A. Yamusa et al., 2018).

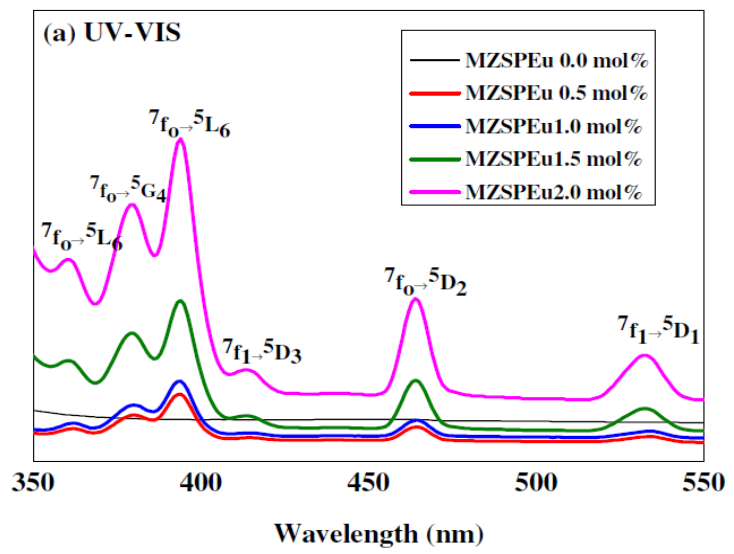

Fig. 3a Absorption spectra of glasses in the visible region.

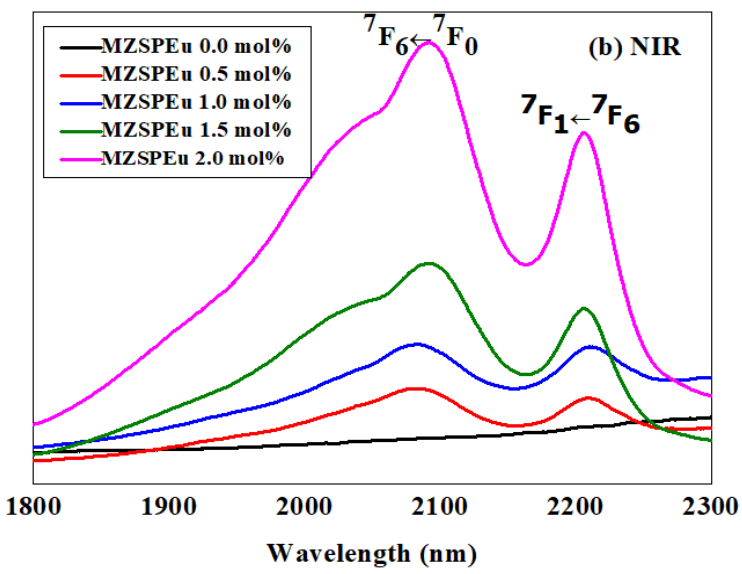

Fig. 3b Absorption spectra of glasses in the NIR region.

Fig. 4 depicts the PL emission spectra of the studied glasses. It comprised of four characteristics peaks positioned at 593, 613, 654 and $701 \mathrm{~nm}$ (Stambouli et al., 2013; Thanh et al., 2012). The intense red peak at $613 \mathrm{~nm}$ is useful for making visible laser.

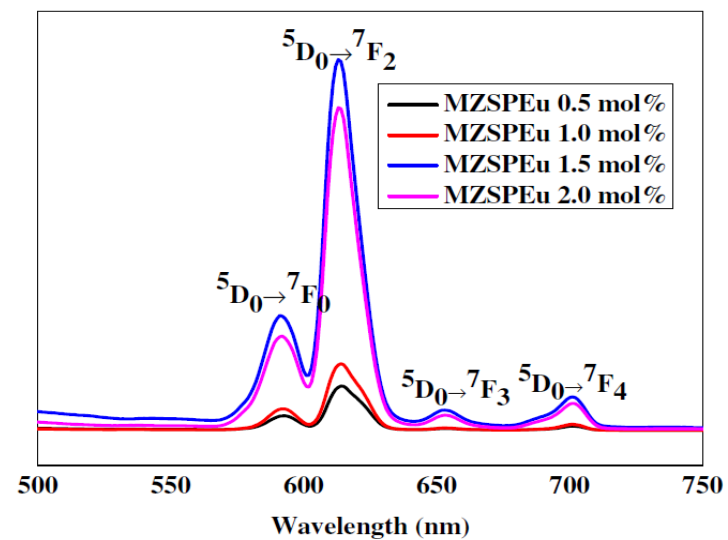

Fig. 4 PL emission spectra of the prepared glasses.

\section{Physical properties}

The physical properties of the prepared glasses were calculated using various relations (Mohammed et al., 2018). Quantities such as density and refractive index were used to calculate other physical parameters including $\mathrm{Eu}^{3+}$ ion concentration, polaron radius, inter-ionic distance, field strength, reflection losses, molar refractivity and electronic polarizability. Glass density measurement provided information about the structural network compactness and coordination number of atoms in the rigid amorphous matrix. Densities of glasses were increased (from 1.54 to $2.80 \mathrm{~g} / \mathrm{cm}^{3}$ ) and the molar volume was decreased (from 7.2 to $4.7 \mathrm{~cm}^{3}$ ) with the raise in $\mathrm{Eu}^{3+}$ ions concentration (Fig. 5), which in turn influenced the polarization factor and field strengths. Glass density was calculated via:

$$
\rho=\frac{a}{a-b} \rho_{x}
$$

where $\rho$ is density, a is sample weight in air b is sample weight in toluene and $\rho \mathrm{x}$ is density of toluene $\left(0.866 \mathrm{gcm}^{-1}\right)$.

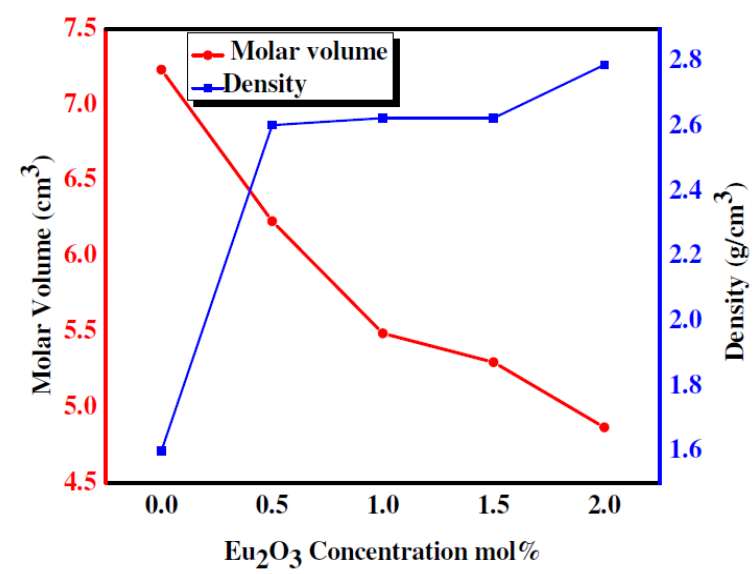

Fig. $5 \mathrm{Eu}_{2} \mathrm{O}_{3}$ contents dependent molar volume and density of glasses.

Polaron radius (reduced) and field strength (enhanced) displayed opposite trend with the increase in $\mathrm{Eu}^{3+}$ ions contents in the glass (Fig. 6).

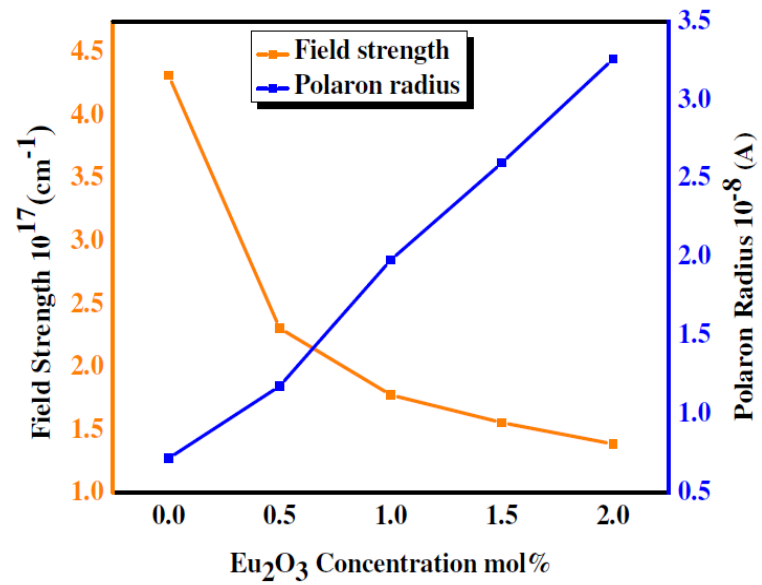

Fig. $6 \mathrm{Eu}_{2} \mathrm{O}_{3}$ contents dependent polaron radius and field strength.

\section{Optical band gap and Urbach energy}

The values of optical band gap (both direct and indirect transitions across the forbidden band) as well as the Urbach energy was calculated from the Tauc's and Urbach plots, respectively. The UV-Vis spectral data at varying photon energy ( $\mathrm{hv}$ ) was used to calculate glass absorption coefficient $(\alpha)$. The Urbach plot was generated ( $\log \alpha$ versus $h v)$ to get the reciprocal of the intercept at the linear region (Y A Yamusa et al., 2018). It is known that glasses have tailing forbidden energy gap with an ill-defined energy band as opposed to crystalline materials. Optical band gap energy corresponding to fundamental absorption was calculated using the expressions: 


$$
\ln \alpha=\frac{h v}{E_{u r b}}-c
$$

where $h v$ is Photon energy,

$$
\alpha h v=B\left(h v-E_{g}\right)^{n}
$$

where $E_{g}$ optical band gap, $\alpha=$ Absorption Coefficient, B is constant.

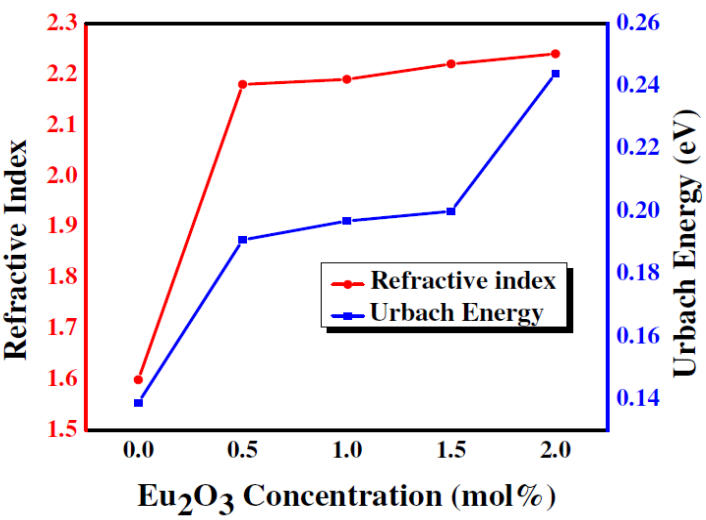

Fig. $7 \mathrm{Eu}_{2} \mathrm{O}_{3}$ contents dependent refractive index and Urbach energy of glasses.
Both the Urbach energy and refractive index (Fig. 7) of the glass system was increased with the increase in $\mathrm{Eu}^{3+}$ ions contents, which were attributed to generation of large number of defects number due to the rupture of bridging oxygen (BO) bonds. The energy band gap for direct transition was increased and for indirect transition increased (Fig. 8) with the increase in $\mathrm{Eu}^{3+}$ ions contents, which were ascribed to creation of large number of $\mathrm{NBO}$ bonds. Table 2 enlists the $\mathrm{Eu}_{2} \mathrm{O}_{3}$ contents dependent Urbach energy, direct and indirect band gap energy of the studied glasses compared to the other literature reports.

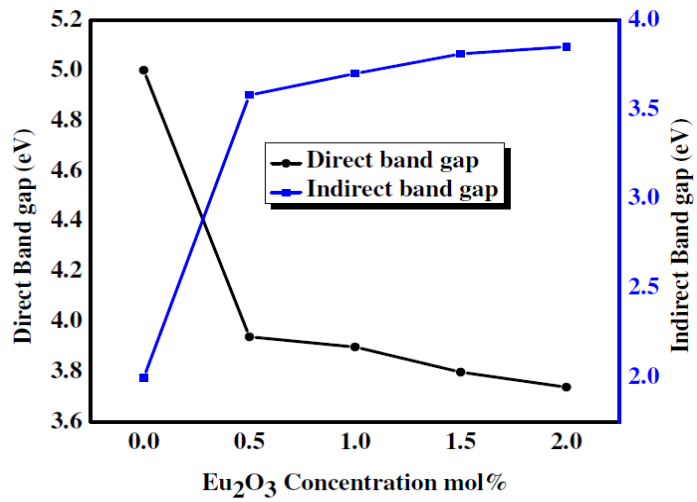

Fig. 8: $\mathrm{Eu}_{2} \mathrm{O}_{3}$ contents dependent direct and indirect band gap energy of the studied glasses.

Table 4 Urbach energy and optical band gap energies of the studied glasses compared to other works.

\begin{tabular}{ccccl}
\hline $\mathbf{E u}^{3+}$ Conc. $(\mathbf{m o l} \%)$ & $\mathbf{E}^{\text {dir }}{ }_{\text {opt }}(\mathbf{e V})$ & $\mathbf{E}^{\text {indir }}{ }_{\text {opt }}(\mathbf{e V})$ & $\Delta \mathbf{E}(\mathbf{e V}$ & Refs. \\
\hline 0.0 & 2.00 & 5.004 & 0.1389 & Present \\
0.5 & 3.58 & 3.94 & 0.1909 & Present \\
1.0 & 3.70 & 3.90 & 0.1969 & Present \\
1.5 & 3.81 & 3.96 & 0.1822 & Present \\
2.0 & 3.85 & 3.74 & 0.2440 & Present \\
$\mathrm{Mg}^{-} \mathrm{P}_{2} \mathrm{O}_{5}$ & 4.52 & 3.70 & 0.40 & (Al-Ani and Higazy, 1991) \\
$\mathrm{MgO}-\mathrm{P}_{2} \mathrm{O}_{5}-\mathrm{ZnSO}_{4}$ & 4.13 & 3.70 & 0.2106 & (Ahmadi et al., 2017) \\
\hline
\end{tabular}

\section{CONCLUSION}

The controlled physical and optical properties of $\mathrm{Eu}^{3+}$ ions doped magnesium-zinc-sulfophosphate glasses were determined. These glasses were prepared using melt-quenching method and characterized at room temperature using different techniques to determine the influence of changing $\mathrm{Eu}_{2} \mathrm{O}_{3}$ concentration on the structure, physical and optical properties of the as quenched glasses. XRD pattern verified the amorphous nature of the prepared samples. Glass density was increased from 2.603 to $2.789 \mathrm{~g} / \mathrm{cm}^{-3}$ with the increase of $\mathrm{Eu}_{2} \mathrm{O}_{3}$ contents. FTIR spectra revealed several characteristics vibrations related to (P-O), (P-O-P), (P-O-P), $\mathrm{P}_{3} \mathrm{O},(\mathrm{P}-\mathrm{O}-\mathrm{P})$ of phosphate networks bonding. The absorption spectra of the glasses showed six intense absorption bands in the visible and two bands in the NIR region. The PL spectra of glasses exhibited four significant peaks. The PL intensity was increased with the increase of $\mathrm{Eu}^{3+}$ content. Such glasses were shown to be beneficial for different applications due to their improved optical properties obtained via composition optimization.

\section{ACKNOWLEDGEMENT}

We are grateful to Malaysian Ministry of Higher Education for providing financial assistance through research grant GUP/RU/UTM/KPT Vot. 18H68 and 17H19.

\section{REFERENCES}

Ahmadi, F., Hussin, R. and Ghoshal, S.K. (2017). Structural and physical properties of $\mathrm{Sm}^{3+}$ doped magnesium zinc sulfophosphate glass. Bulletin of Materials Science. 40(6), 1097-1104.

Al-Ani, S.K.J. and Higazy, A.A. (1991). Study of optical absorption edges in MgO- $\mathrm{P}_{2} \mathrm{O}_{5}$ glasses. Journal of Materials Science. 26(13), 3670-3674.

Ashur, Z., Mahraz, S., Sahar, M.R., Ghoshal, S.K. and Dousti, M.R. (2013). Concentration dependent luminescence quenching of $\mathrm{Er}^{3+}$-doped zinc. Journal of Luminescence. 144, 139-145.

Dimitrov, V., Sakka and S (1996). Electronic oxide polarizability and optical basicity of simple oxides. Applied Physics. 79, 1736-1740.

Koester, C.J. and Snitzer, E. (1964). Amplification in a fiber laser. Applied Optics. 3 (10), 1182.

Mohammed, A., Hussin, R., Ahmad, N.E. and Yamusa, Y.A. (2018). Optik Samarium doped calcium sulfate ultra-phosphate glasses: Structural, physical and luminescence investigations. Optik - International Journal for Light and Electron Optics. 172(May), 1162-1171.

Mott, N.F. and Davis, E.A. (2012). Electronic Processes in Non-Crystalline Materials, Oxford University Press.

Rasool, S.N., Moorthy, L.R., and Jayasankar, C.K. (2013). Spectroscopic investigation of $\mathrm{Sm}^{3+}$ doped phosphate based glasses for reddish-orange emission. Optics Communications. 311, 156-162.

Reis, S.T., Faria, D.L.A., Martinelli, J.R., Pontuschka, W.M., Day, D.E., Partiti, C.S.M. (2002). Structural features of lead iron phosphate glasses. Journal of Non-Crystalline Solids. 304, 188-194. 
Reza Dousti, M., Sahar, M.R., Ghoshal, S.K., Amjad, R.J. and Samavati, A.R. (2013). Effect of $\mathrm{AgCl}$ on spectroscopic properties of erbium doped zinc tellurite glass. Journal of Molecular Structure. 1035, 6-12.

Saruwatari, M., and Izawa, T. (1974). Nd-glass laser with three-dimensional optical waveguide. Applied Physics Letters. 24, 603-605.

Snitzer, E. (1961). Optical maser action of $\mathrm{Nd}^{+3}$ in a barium crown glass. Physical Review Letters. 7(12), 444-446.

Soga, N., Hirao, K., Yoshimoto, M., Yamamoto, H. (1988). Effects of densification on fluorescence spectra and glass structure of $\mathrm{Eu}^{3+}$-doped borate glasses. Applied Physics. 63, 4451-4454.

Stambouli, W., Elhouichet, H., Gelloz, B. and Férid, M. (2013). Optical and spectroscopic properties of Eu-doped tellurite glasses and glass ceramics. Journal of Luminescence. 138, 201-208.

Thanh, N.T., Quang, V.X., Tuyen, V.P., Tam, N. V., Hayakawa, T. and Huy,
B.T. (2012). Role of charge transfer state and host matrix in $\mathrm{Eu}^{3+}$-doped alkali and earth alkali fluoro-aluminoborate glasses. Optical Materials. 34 (8), 1477-1481.

Yajima, H., Kawase, S., Sekimoto, Y. (1972). Amplification at $1.06 \mu \mathrm{m}$ using a Nd: Glass thin-film waveguide. Applied Physics Letters. 21, 407-409.

Yamusa, Y.A., Hussin, R., Shamsuri, W.N.W., Dalhatu, S.A., Aliyu, A.M. and Bulus, I. (2018). Structural, optical and physical properties of $\mathrm{Dy}^{3+}$ ions in barium sulphate borophosphate glasses for generation of white light. International Journal of Modern Physics B. 32, 1850213 - 1850232

Yamusa, Y.A., Hussin, R., Shamsuri, W.N.W., Tanko, Y.A. and Jupri, S.A. (2018). Impact of $\mathrm{Eu}^{3+}$ on the luminescent, physical and optical properties of $\mathrm{BaSO}_{4}-\mathrm{B}_{2} \mathrm{O}_{3}-\mathrm{P}_{2} \mathrm{O}_{5}$ glasses. Optik - International Journal for Light and Electron Optics. 164, 324-334. 